\title{
C3a and Its Receptor C3aR Are Detectable in Normal Human Epidermal Keratinocytes and Are Differentially Regulated via TLR3 and LL37
}

\author{
Susanne Mommert ${ }^{\mathrm{a}}$ Lisa Doenni ${ }^{\mathrm{a}}$ Phillip Szudybill $^{\mathrm{a}}$ Christoph Zoeller $^{\mathrm{b}}$ \\ Frerk Hinnerk Beyer $^{\mathrm{a}}$ Thomas Werfel $^{\mathrm{a}}$ \\ aDivision of Immunodermatology and Allergy Research, Department of Dermatology and Allergy, Hannover \\ Medical School, Hannover, Germany; ${ }^{b}$ Department of Pediatric Surgery, Hannover Medical School, Hannover, \\ Germany
}

\section{Keywords}

C3a receptor $\cdot$ Complement system $\cdot$ Keratinocytes $\cdot$ Pattern recognition receptors

\begin{abstract}
To study the molecular interplay between TLRs and complement representing ancient danger-sensing mechanisms, we examined the regulation of the $\mathrm{C} 3 \mathrm{a}$ /anaphylatoxin $\mathrm{C} 3 \mathrm{a}$ receptor ( $\mathrm{C} 3 \mathrm{aR}$ ) axis in normal human epidermal keratinocytes (NHEKs) by treatment with different TLR ligands. Protein staining followed by flow cytometry revealed highly constitutive intracellular expression levels of the C3aR in NHEKs. Stimulation with Poly I:C up-regulated C3aR mRNA and intraand extracellular expression in NHEKs which showed functional relevance by up-regulating CXCL10 and down-regulating $\mathrm{C} 3$ expression in response to $\mathrm{C} 3 \mathrm{a}$. mRNA and protein levels of $\mathrm{C} 3$ and protease cathepsin $\mathrm{L}$ (CTSL) that can cleave C3 were up-regulated by the TLR3 ligand Poly I:C. Enhanced intracellular expression levels of the biologically active C3 fragment $(\mathrm{C} 3 \mathrm{a})$, in response to TLR3 stimulation were also detectable in NHEKs. Cathelicidin antimicrobial peptide LL37 potentiated Poly I:C-induced C3aR, C3, and CTSL up-regulation.
\end{abstract}

karger@karger.com www.karger.com/jin

Karger $\stackrel{\text { ' }}{5}$

GOPEN ACCESS
C) 2021 The Author(s)

Published by S. Karger AG, Basel

This article is licensed under the Creative Commons AttributionNonCommercial-NoDerivatives 4.0 International License (CC BY NC-ND) (http://www.karger.com/Services/OpenAccessLicense) Usage and distribution for commercial purposes as well as any distribution of modified material requires written permission.
In conclusion, we point to a role of TLR3 to promote up-regulation of C3aR, C3, and CTSL expression levels and generation of C3a. Our data provide evidence that local generation and activation of complement components as described for T cells or myeloid cells represent a scenario which may take place in a similar way in NHEKs.

(c) 2021 The Author(s)

Published by S. Karger AG, Basel

\section{Introduction}

The complement system acts as an efficient dangersensing system, protecting the host from infectious microorganisms and maintaining tissue homeostasis by clearance of altered or dying cells [1]. A growing body of evidence indicates that TLRs and complement as key innate defense systems communicate with each other. Cross-activation of complement and TLR signaling pathways influences innate and adaptive immune responses [2]. Targeting danger pattern recognition molecules, which are expressed, for example, on microbial invaders or endogen on dying cells, by receptors of the complement system, provokes complement activation in a linear 
cascade of separate pathways [3]. The pathway-specific activation of the third component of the complement $\mathrm{C} 3$ leads to the formation of the $\mathrm{C} 3$ convertase, which cleaves $\mathrm{C} 3$ into the 2 effector molecules anaphylatoxin active $\mathrm{C} 3$ fragment $(\mathrm{C} 3 \mathrm{a})$ and opsonin $\mathrm{C} 3 \mathrm{~b}$. Binding to its specific $\mathrm{G}$ protein-coupled (anaphylatoxin $\mathrm{C} 3 \mathrm{a}$ receptor) $\mathrm{C} 3 \mathrm{aR}$, anaphylatoxin $\mathrm{C} 3 \mathrm{a}$ exerts potent immunomodulatory effects: triggering mast cell degranulation, activating leukocytes to release cytokines or chemokines, and acting as a chemoattractant that guides mast cells, neutrophils, monocytes, or macrophages toward sites of inflammation [3-5].

Keratinocytes use TLRs to recognize pathogen-associated molecular patterns, which are expressed on foreign or on endogenously produced agents released from damaged cells. Triggering the TLRs leads to activation of cell signaling and subsequent innate and adaptive immune responses [6]. The endosomally expressed TLR3 recognizes double-stranded RNA (dsRNA) and is thought to play a role in virus infection, in particular in herpes simplex virus infection. Herpes simplex virus produces dsRNA during genome replication in infected cells [7]. TLR3 is highly expressed around herpetic vesicles in the skin [8]. In addition to its role in viral defense, an important function of TLR3 for skin barrier repair and maintenance has been reported. TLR3 is also activated by dsRNA released from injured or necrotic keratinocytes and triggers beyond cytokine, chemokine or TSLP release some elements of skin barrier formation such as epidermal lipid production during the process of repair [9]. Patients suffering from atopic dermatitis tend to have disseminated viral infections such as eczema herpeticum [10]. In lesional skin of these patients, self dsRNA from damaged cells or viral dsRNA may present a strong trigger factor to activate TLR3, leading to pronounced gene expression $[7,11]$.

In human skin, C3 is produced by dermal macrophages [12] and by keratinocytes [13]. High expression of $\mathrm{C} 3$ in the skin of Th1/Th17-polarized psoriasis and high concentrations of its cleavage product C3a in the scales of psoriasis patients were described [14]. C3aR is expressed on both human-activated $\mathrm{T}$ cells [15] and on macrophages [12]. Expression and up-regulation of C3aR by IFN- $\gamma$ and IFN- $\alpha$ on human keratinocytes were detected by us in a previous report [13]. Importantly, while the main source of circulating complement components is the liver, a newly developed concept focused on local complement activation and modulation of the immune response. Intracellular stores of C3 were detected in lymphoid, myeloid, and non-myeloid cells. Upon danger sensing in T cells and also in monocytes, protease cathep$\sin$ L (CTSL) processed cleavage of C3 into C3a and C3b. The intracellular complement activation and receptor system are then shuttled to the cell surface and could contribute to effector functions [16]. The expression of C3aR on human keratinocytes may allow these cells to respond to paracrine- or autocrine-derived complement products. The aim of our study was to investigate the molecular interplay between TLRs and complement by stimulating normal human epidermal keratinocytes (NHEKs) with different TLR ligands and to analyse the expression profile of local complement components such as $\mathrm{C} 3 \mathrm{aR}, \mathrm{C} 3$, and CTSL at mRNA and protein level and the generation of C3a.

\section{Materials and Methods}

\section{Isolation and Culture of Primary NHEKs}

NHEKs were prepared from juvenile foreskin, as described previously $[17,18]$. Briefly, the foreskin was cut into pieces and incubated overnight at $37^{\circ} \mathrm{C}$ in $2.4 \mathrm{U}$ of Dispase II (Roche, Mannheim, Germany). The next day, the epidermis was separated from the dermis and placed for $20 \mathrm{~min}$ at $37^{\circ} \mathrm{C}$ in EDTA (0.02\%)-trypsin $(0.05 \%)$ solution (PAN-Biotech, Aidenbach, Germany). After stopping the trypsin reaction by adding FCS (PromoCell, Heidelberg, Germany), the cell suspension was filtered through a sterile gauze $(40 \mathrm{~mm})$ and washed 2 times in PBS. The obtained singlecell suspension of NHEKs was incubated in the serum-free growth medium Keratinocyte Growth Medium 2 Kit (PromoCell) at $37^{\circ} \mathrm{C}$ in a humidified atmosphere containing $5 \% \mathrm{CO}_{2}$. Normally, when cells in passages 3-7 reached $70-80 \%$ confluence, they were used for experiments or further passaged.

\section{Differentiation of NHEKs by Increased Calcium}

\section{Concentrations}

To study the expression of the complement components in NHEKs after $\mathrm{Ca}^{2+}$-induced differentiation of the cells, $1.30 \mathrm{mM}$ $\mathrm{CaCL}_{2}$ was added to the medium in which the keratinocytes were cultured for 2-4 days. In NHEKs differentiated in low $\mathrm{Ca}^{2+}$ concentrations $(0.06 \mathrm{mM})$ and in NHEKs cultured with high $\mathrm{Ca}^{2+}$ concentrations $(1.36 \mathrm{mM})$, the mRNA expression of the differentiation marker filaggrin, which is characteristically highly expressed in mature keratinocytes, and the marker for undifferentiated keratinocytes, the type I keratin K14, was analysed by qPCR. qPCRs of C3aR, C3, and CTSL were performed with immature and mature NHEKs.

Flow Cytometric Analysis of Intracellular Expression of C3aR, C3a, or CTSL

NHEKs were stimulated with Poly I:C (Sigma-Aldrich) (10 $\mu \mathrm{g} /$ $\mathrm{mL}$ ) for expression analysis of the complement components for different time periods, as indicated in the relevant figures or left unstimulated. We used for the non-stimulated baseline control and for the negative control the Poly I:C solvent in all experiments. For solving Poly I:C, we used PBS according to the manufacturers' instructions. To demonstrate the mode of action of the 
lysosomal protease CTSL, which plays a role in generation of C3a, NHEKs were treated with a selective CTSL inhibitor $(40 \mathrm{ng} / \mathrm{mL})$ (Enzo Life Science, Exeter, UK). Prior to flow cytometric analysis, keratinocytes were detached by incubating with $0.0025 \%$ EDTA (PAN-Biotech) for 3-5 min, following an incubation period with HyQTase (Perbio, Bonn, Germany) up to $10 \mathrm{~min}$. For intracellular staining, keratinocytes were fixed and permeabilized using Cytofix/Cytoperm (BD Bioscience). Phycoerythrin-labelled C3aR monoclonal mouse IgG2b antibody $(1 \mu \mathrm{g} / \mathrm{mL}$ ) (BioLegend, San Diego, CA, USA) was used for staining extra- and intracellular expressed $\mathrm{C} 3 \mathrm{aR}$. To detect the C3a neo-epitope, which is expressed in activation products and not present in the individual native components, a monoclonal mouse IgG1 antibody $(1 \mu \mathrm{g} /$ $\mathrm{mL}$ ) from Hycult Biotech, Uden, The Netherlands, was used. Intracellular expressed CTSL was stained with a monoclonal mouse IgG1 antibody $(1 \mu \mathrm{g} / \mathrm{mL})$ obtained from Abcam, Cambridge, UK. As secondary antibody, goat anti-mouse $\operatorname{IgG~} \mathrm{F}(\mathrm{ab})_{2}$ fragmentphycoerythrin (Jackson Immuno Research, UK) was used to detect the unconjugated monoclonal antibodies. Sample acquisition was performed by flow cytometry (FACS Calibur, Becton Dickinson, Heidelberg, Germany), and mean fluorescence intensities were calculated by CellQuest Pro software (Becton Dickinson). Control staining was performed with matched isotypes used in the same final concentration as corresponding staining antibodies (Phycoerythrin-labelled mouse IgG2b (BioLegend) and unlabelled mouse IgG1 (R\&D Systems).

\section{Real-Time Quantitative LightCycler RT-PCR}

Human keratinocytes were seeded in 48 -well plates at a density of $1.5 \times 10^{4}$ cells per well and treated with LPS (Sigma-Aldrich) (50 $\mathrm{ng} / \mathrm{mL}), \mathrm{CpG}$ ODN2216 (InvivoGen, San Diego, CA, USA) $(2 \mu \mathrm{g} /$ $\mathrm{mL})$, TLR3 ligand Poly I:C (Sigma-Aldrich) $(10 \mu \mathrm{g} / \mathrm{mL})$, or LL-37 (InvivoGen) $(1.0 \mu \mathrm{M})$ for $24 \mathrm{~h}$ or for different time periods, as depicted in respective figures. Total RNA was isolated using the RNeasy kit (Qiagen, Hilden, Germany) or the InnuPrep Micro RNA kit (Analytik Jena, Jena, Germany) according to the manufacturers' instructions. The cDNA was synthesized by reverse transcription (QuantiTect reverse transcription kit, Qiagen, Germany). Real-time qPCR was performed with Quantitect ${ }^{\circledR}$ primer assays for CTSL (QT01664978), C3 (QT01680413) or (QT00089698), C3aR (QT00090398), filaggrin (QT00092218), keratin 14 (QT000052283), and PGK1 (phosphoglycerate kinase 1) (QT00013776) using SYBR ${ }^{\circledR}$ Green according to the manufacturers' instructions (Qiagen, Hilden, Germany) using the LightCycler 480.

The amount of the target mRNA relative to the amount of the reference PGK1 mRNA in the same sample (target/reference ratio) was calculated using the comparative Ct method also known as the [delta] [delta] Ct method provided by Relative Quantification Software (Roche Molecular Biochemicals). The Ct values of both the calibrator and the samples of interest are normalized to the appropriate endogenous housekeeping gene PGK1.

\section{Enzyme-Linked Immunosorbent Assay}

Human keratinocytes were seeded in 48-well plates at a density of $1.5 \times 10^{4}$ cells per well and treated with TLR3 ligand Poly I:C (Sigma-Aldrich) $(10 \mu \mathrm{g} / \mathrm{mL})$ for 24,48 , and $72 \mathrm{~h}$. Cell-free supernatants were taken. C3 and CXCL10 ELISAs were performed according to the manufacturers' instructions (Abcam and R\&D, respectively).

\section{Immunohistology}

Paraffin-embedded tissue sections ( $5 \mu \mathrm{m}$ thick) from skin derived from healthy persons were made. Immunohistology was performed using the components by Dako (Dako, Santa Clara, CA, USA) according to the manufacturers' instructions. Briefly, target retrieval solution ph 6 (Dako) was used for heat-induced $\left(120^{\circ} \mathrm{C} / 20\right.$ min) epitope retrieval.

Growth chambers called chamber tek slides which were specially developed for microscopy of in situ cell culture of adherent cells were used. NHEKs were grown on a standard microscope slide with a growth chamber $\left(1.5 \times 10^{4}\right.$ cells per well per chamber $)$ in low $\mathrm{Ca}^{2+}$ concentrations $(0.06 \mathrm{mM})$ and in high $\mathrm{Ca}^{2+}$ concentrations $(1.36 \mathrm{mM})$ for 3 days. The chamber was removed, and the NHEKs on the microscope slide were fixed with $4 \%$ formaldehyde and processed for immunohistochemistry.

Immunohistochemistry: The tissue sections and microscope slides were then overlaid with pre-determined optimal concentrations of anti-C3aR $(1 \mu \mathrm{g} / \mathrm{mL})$ (rabbit polyclonal, Abcam, Cambridge, UK), anti-C3 (1 $\mu \mathrm{g} / \mathrm{mL})$ (rabbit polyclonal, Abcam, Cambridge, UK), anti-C3a/C3a desArg neoepitope $(2 \mu \mathrm{g} / \mathrm{mL}$ ) (monoclonal mouse IgG1, Hycult Biotech, Uden, The Netherlands), and anti-CTSL $(0.5 \mu \mathrm{g} / \mathrm{mL})$ (monoclonal mouse IgG1, Abcam, Cambridge, UK) for $24 \mathrm{~h}$. In all experiments, staining was performed with the corresponding isotype of the same final concentration as a control. Detection was performed for primary mouse and rabbit antibodies with the Dako EnVision kit HRP-APC (Dako) according to the manufacturers' instructions. Finally, the sections were counterstained by H\&E staining according to common methods and mounted in Roti-Mount Aqua (Roth, Karlruhe, Germany). Microscopy was performed with an Olympus $\mathrm{BH} 2$ microscope, and images were created using an Olympus SC30 camera and respective software (Olympus).

\section{Statistics}

For statistical analyses, software GraphPad Prism version 8.0 was used (San Diego, CA, USA). Wilcoxon's matched-pairs signed rank test or Friedman-Dunn's multiple comparison test selected pairs was performed for the data with non-parametric distribution. The median is shown in the graphs. A $p$ value $<0.05$ was regarded as statistically significant $\left(p<0.05\right.$ was labelled with ${ }^{*}, p<$ 0.01 was labelled with ${ }^{* *}, p<0.001$ was labelled with $\left.* * *\right)$.

\section{Results}

\section{Poly I:C Up-Regulates C3aR mRNA Expression in NHEKs}

Human keratinocytes express different TLRs on the cell surface or on the surface of the endosomal compartment, recognizing distinct types of conserved microbial structures. TLR4 that is expressed on the cell surface responds to LPS. TLR9 and TLR3 are located intracellularly in the endosomal compartment and respond to $\mathrm{CpG}$ or Poly I:C, respectively.

We detected that $\mathrm{C} 3 \mathrm{aR}$ mRNA was constitutively expressed in NHEKs and selectively up-regulated by stimu- 


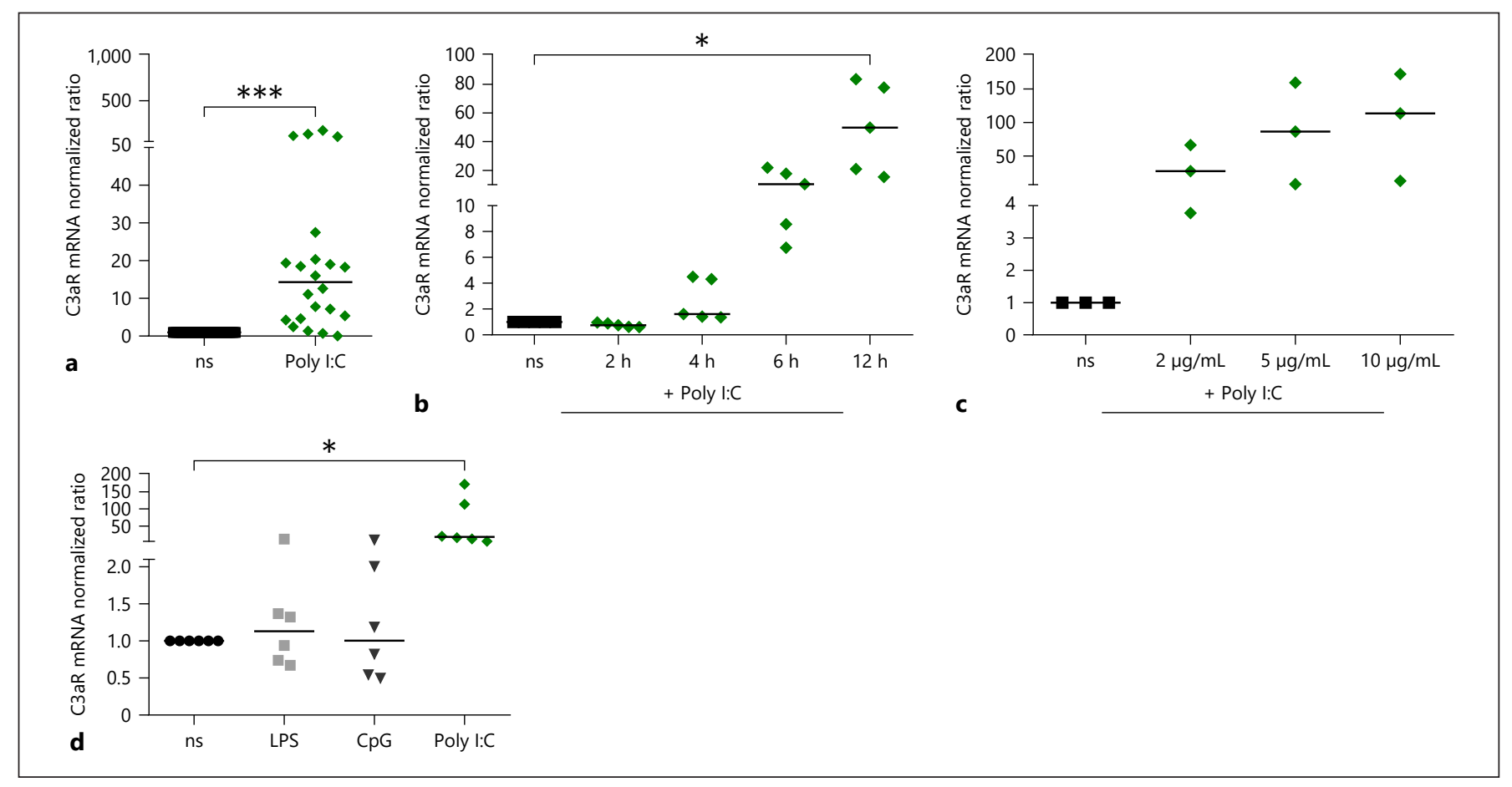

Fig. 1. TLR3 ligand Poly I:C up-regulates C3aR mRNA expression in NHEKs. C3aR mRNA expression is shown: a NHEKs derived from foreskin of different donors in different passages were stimulated with Poly I:C $(10 \mu \mathrm{g} / \mathrm{mL})$ for $24 \mathrm{~h}$ or left unstimulated. b NHEKs were stimulated with Poly I:C $(10 \mu \mathrm{g} / \mathrm{mL})$ for different time periods as indicated. c NHEKs were stimulated with different concentrations of Poly I:C ranging from 2 to $10 \mu \mathrm{g} / \mathrm{mL}$ as indicated for $24 \mathrm{~h}$. d NHEKs were cultured and stimulated with LPS/ TLR4 (50 $\mu \mathrm{g} / \mathrm{mL})$, CpG oligonucleotide/TLR9 $(2 \mu \mathrm{g} / \mathrm{mL})$, or Poly I:C/TLR3 $(10 \mu \mathrm{g} / \mathrm{mL})$ for $24 \mathrm{~h}$ or left unstimulated. C3aR mRNA expression was analysed by qPCR and calculated by the [delta]

lating TLR3 with Poly I:C for $24 \mathrm{~h}$ (Fig. 1a). Performing time kinetics we showed that $\mathrm{C} 3 \mathrm{aR}$ mRNA was rapidly up-regulated by Poly I:C within $4 \mathrm{~h}$ and with high expression levels after 12-h stimulation time (Fig. 1b). In doseresponse experiments, we observed that the concentration of $10 \mu \mathrm{g} / \mathrm{mL}$ Poly I:C was most effective to up-regulate the C3aR by trend (Fig. 1c).

Besides stimulation with Poly I:C, we investigated the regulation of $\mathrm{C} 3 \mathrm{aR}$ mRNA expression in response to other microbial components such as LPS or CpG. NHEKs were stimulated with LPS $(50 \mathrm{ng} / \mathrm{mL})$ and CpG $(2 \mu \mathrm{g} / \mathrm{mL})$ in comparison to Poly I:C $(10 \mu \mathrm{g} / \mathrm{mL})$ for $24 \mathrm{~h}$ or left unstimulated. As shown in Figure 1d, the C3aR mRNA expression was up-regulated by Poly I:C but not regulated by LPS or by CpG. [delta] Ct method normalized to the ns samples. Phosphoglycerate kinase 1 was used as a reference gene for all PCRs. Significant differences, as determined by the Wilcoxon matched-pairs signed rank test (a) or by Friedman-Dunn's multiple comparison test selected pairs (b, d), are indicated as follows: ${ }^{*} p<0.05$; ${ }^{* * *} p<0.001$; medians are shown in the graphs. $n=22$ experiments from 7 independent donors (a); $n=5$ experiments from 4 independent donors (b); $n=3$ experiments from 1 donors (c); $n=6$ experiments from 3 independent donors (d). NHEK, normal human epidermal keratinocyte; ns, non-stimulated; $\mathrm{C} 3 \mathrm{aR}$, anaphylatoxin $\mathrm{C} 3 \mathrm{a}$ receptor.

\section{C3aR Is Highly Expressed Intracellularly in Unstimulated NHEKs and Is Up-Regulated Intracellularly as well as on the Cell Surface of NHEKs upon TLR3 Stimulation}

The intra- and extracellular expression of C3aR was analysed by flow cytometry on NHEKs in unstimulated and in Poly I:C-stimulated cells. We detected high levels of intracellular protein expression of C3aR. Stimulation with Poly I:C for 24, 48, and $72 \mathrm{~h}$ showed an up-regulation of $\mathrm{C} 3 \mathrm{aR}$ expression after all stimulation periods, which was significant after a stimulation period of $48 \mathrm{~h}$ (Fig. 2a, b). NHEKs were stimulated with LPS (50 $\mathrm{ng} / \mathrm{mL}$ ) and CpG $(2 \mu \mathrm{g} / \mathrm{mL})$ in comparison to Poly I:C $(10 \mu \mathrm{g} / \mathrm{mL})$ for $48 \mathrm{~h}$ or left unstimulated. In accordance with the mRNA data, we could also show that intracellular C3aR expression was selectively up-regulated by Poly I:C but not regulated by LPS or by CpG (Fig. 2c). 


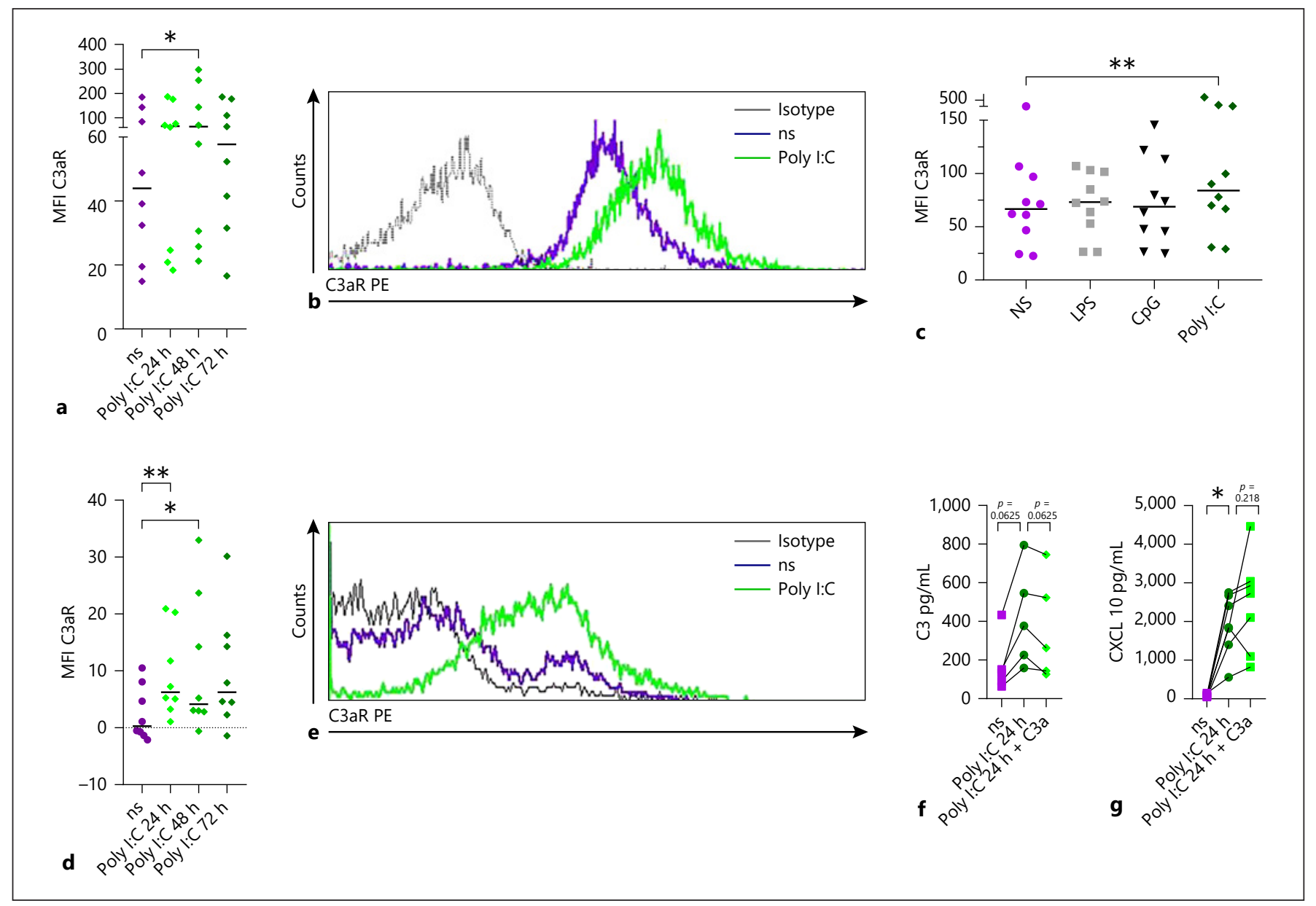

Fig. 2. C3aR is highly expressed intracellularly in unstimulated NHEKs and is up-regulated intracellularly as well as on the cell surface of NHEKs upon TLR3 stimulation. NHEKs were stimulated with Poly I:C (10 $\mu \mathrm{g} / \mathrm{mL})$ for 24,48 , and $72 \mathrm{~h}$ or left unstimulated. Keratinocytes were stained intracellularly and extracellularly with phycoerythrin-labelled C3aR monoclonal mouse IgG2b antibody. Expression of C3aR was analysed by flow cytometry, and MFIs were calculated. a Eight intracellular staining experiments from 7 different donors are shown. b One representative histogram of intracellular C3aR expression is shown. d Eight extracellular staining experiments from 7 different donors are shown. e One representative histogram of extracellular C3aR expression is shown. The dotted line represents the matched isotype control, the violet line represents the ns cells, and the green line represents the Poly I:C-stimulated cells. c NHEKs were cultured and stimulated with LPS/TLR4 $(50 \mu \mathrm{g} / \mathrm{mL})$, CpG oligonucleotide/TLR9 (2 $\mu \mathrm{g} / \mathrm{mL})$, or Poly I:C/TLR3 $(10 \mu \mathrm{g} / \mathrm{mL})$ for $48 \mathrm{~h}$ or left unstimulated,

In contrast, we found that $\mathrm{C} 3 \mathrm{aR}$ was constitutively expressed only in low density on the cell surface of NHEKs. A significant up-regulation of $\mathrm{C} 3 \mathrm{aR}$ expression upon Poly I:C on the cell surface was detectable after a stimulation period of 24 and $48 \mathrm{~h}$ (Fig. 2d, e). Very limited data and C3aR expression was analysed intracellularly by flow cytometry. f, $\mathbf{g}$ NHEKs were stimulated with Poly I:C for $24 \mathrm{~h}$ or left unstimulated. Poly I:C-stimulated cells were washed, and new medium was added. Then, the cells were stimulated with C3a $(1 \mu \mathrm{g} /$ $\mathrm{mL}$ ) for $24 \mathrm{~h}$ or left unstimulated. The supernatants were all collected at the same time point. $\mathbf{f}$ The release of $\mathrm{C} 3$ was measured by the ELISA technique. $\mathbf{g}$ The release of CXCL10 was measured by the ELISA technique. Significant differences, as determined by the Wilcoxon matched-pairs signed rank test $(\mathbf{f}, \mathbf{g})$ or by FriedmanDunn's multiple comparison test selected pairs (a-d), are indicated as follows: ${ }^{*} p<0.05{ }^{* *} p<0.01$; medians are shown in the graphs. $n=10$ experiments from 10 independent donors (c); $n=5$ experiments from 5 independent donors (f); $n=7$ experiments from 5 independent donors (g). NHEK, normal human epidermal keratinocyte; ns, non-stimulated; MFI, mean fluorescence intensity; C3aR, anaphylatoxin C3a receptor; $\mathrm{C} 3 \mathrm{a}$, active $\mathrm{C} 3$ fragment.

exist on the role of $\mathrm{C} 3 \mathrm{a}$ or $\mathrm{C} 3 \mathrm{aR}$ to influence TLR3-dependent cytokine, chemokine productions. We could show here that the up-regulation $\mathrm{C} 3 \mathrm{aR}$ is of functional relevance since we observed that enhanced expression of C3aR on NHEKs via Poly I:C showed a tendency to make 


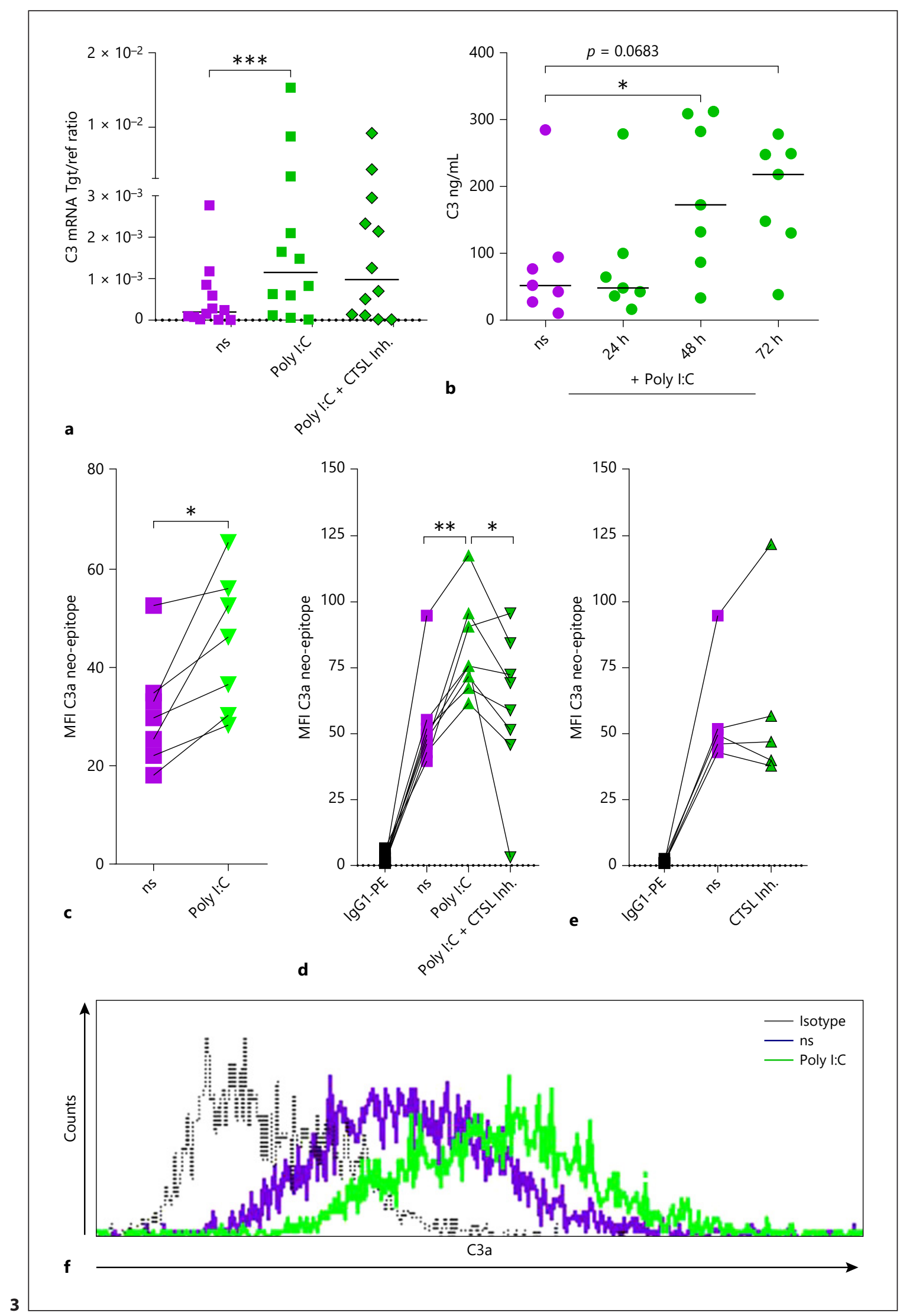

(For legend see next page.) 
the cells more susceptible to C3a stimulation. NHEKs were first stimulated with Poly I:C. After several washing steps and medium changes, one part of the cells was stimulated with $\mathrm{C} 3 \mathrm{a}$ for $24 \mathrm{~h}$, which led to a down-regulation of $\mathrm{C} 3$ production which was nearly significant, confirming a functional effect of C3aR induction in Poly I:C-stimulated cells and a trend for a pronounced response to $\mathrm{C} 3 \mathrm{a}$ in Poly I:C-activated NHEKs (high expression of C3aR) (Fig. 2f).

In contrast to our previously published observation of an increase in CCL2, CXCL8 and CXCL10 upon C3a stimulation after induction of C3aR by IFN- $\gamma$ and IFN- $\alpha$ [13], we did not observe an up-regulation of CCL2 and CXCL8 by C3a after induction of C3aR by Poly I:C (data not shown). However, production of CXCL10 was induced by Poly I:C and potentiated by trend by stimulating the NHEKs with C3a (Fig. 2g).

\section{Poly I:C Up-Regulates C3 mRNA Expression and C3}

Protein Secretion and Induces the Generation of the

Active Fragment C3a in NHEKs

To determine whether enhanced expression of $\mathrm{C} 3 \mathrm{aR}$ by Poly I:C goes in line with an induction of $\mathrm{C} 3$, we stimulated NHEKs with Poly I:C $(10 \mu \mathrm{g} / \mathrm{mL})$ for different time periods or left the cells unstimulated and analysed C 3 expression and processing. We detected that $\mathrm{C} 3 \mathrm{mRNA}$ and protein were constitutively expressed in NHEKs and selectively up-regulated by stimulating TLR3 with Poly I:C. C3 mRNA expression was up-regulated after 24-h stimulation. Poly I:C fostered C3 protein production time dependently with an increase after $48 \mathrm{~h}$ and after $72 \mathrm{~h}$ (Fig. 3a, b). To explore if $\mathrm{C} 3$ is processed intracellularly by generating the biologically active fragment $\mathrm{C} 3 \mathrm{a}$, we

Fig. 3. TLR3 ligand Poly I:C up-regulates C 3 mRNA and protein expression in NHEKs. Intracellular generation of the biologically active fragment of $\mathrm{C} 3$, the $\mathrm{C} 3 \mathrm{a}$ neo-epitope, is enhanced in parallel via TLR3 in NHEKs. NHEKs were stimulated with Poly I:C (10 $\mu \mathrm{g} /$ $\mathrm{mL}$ ) for $24 \mathrm{~h}$ (C3 mRNA and C3a generation) and for different time points as indicated ( $\mathrm{C} 3$ protein) or left unstimulated. For a, d, and e, a selective and reversible inhibitor of human CTSL was used to prove if the enhanced generation of $\mathrm{C} 3 \mathrm{a}$ neo-epitope is dependent on the presence of CTSL. (a) C3 mRNA expression was analysed by qPCR and tgt/ref ratio was calculated by the [delta] Ct method. Phosphoglycerate kinase 1 was used as reference gene. b Cell-free supernatants were collected after different time periods, and C3 concentrations were determined by ELISA. c-e C3a was stained intracellularly with a monoclonal mouse IgG1 antibody against a specific epitope of this cleavage product of $\mathrm{C} 3$ called neo-epitope. The expression of C3a was analysed by flow cytom- stained the Poly I:C-stimulated cells with a monoclonal mouse IgG1 antibody, which recognizes a specific epitope of human $\mathrm{C} 3 \mathrm{a} / \mathrm{C} 3 \mathrm{a}-\mathrm{des} A r g$ that is formed upon cleavage of the complement protein C3 into C3a and C3b. These activation products of the complement contain epitopes, which are not present in the individual native components and therefore are called neo-epitopes. We detected the presence of C3a neo-epitope intracellularly in NHEKs by flow cytometry. The generation of C3a was significantly up-regulated after stimulation with Poly I:C for $24 \mathrm{~h}$ (Fig. 3c, f).

Since we observed up-regulation of C3aR expression, up-regulation of $\mathrm{C} 3$ at mRNA and protein levels, and generation of C3a by Poly I:C in NHEKs, we hypothesized an influence of Poly I:C on intrinsic C3 convertase-independent pathways leading to intracellular C3 cleavage into biologically active $\mathrm{C} 3 \mathrm{a}$ and $\mathrm{C} 3 \mathrm{~b}$ fragments. Liszewski et al. [16] showed that in particular, $\mathrm{T}$ cells, but also myeloid and non-myeloid cells such as epithelial or endothelial cells, contain stores of $\mathrm{C} 3$ and the active fragment $\mathrm{C} 3 \mathrm{a}$, and these cells express C3aR intracellularly. CTSL was identified as protease with the capacity to cleave C3, leading to active C3a fragments in T cells [16].

Remarkably, simultaneous incubation of NHEKs with a selective CTSL inhibitor blocked the Poly I:C-induced generation of C3a (Fig. 3d), whereas the constitutive expression of intracellularly localized C3a was not influenced after treatment with the CTSL inhibitor (Fig. 3e). In addition, we measured mRNA expression levels of $\mathrm{C} 3$ in NHEKs, which were treated under the same conditions. As depicted in Figure 3a, Poly I:C significantly induced up-regulation of $\mathrm{C} 3 \mathrm{mRNA}$, which was not inhibited by simultaneous incubation of the cells with the

etry, and MFIs were calculated. f One representative histogram of intracellular C3a expression is shown. The dotted line represents the matched isotype control, the violet line represents the ns cells, and the green line represents the Poly I:C-stimulated cells. Significant differences, as determined by the Wilcoxon matched-pairs signed rank test (a, c, d) or by Friedman-Dunn's multiple comparison test selected pairs (b), are indicated as follows: ${ }^{*} p<0.05$; ${ }^{* *} p<0.01$; ${ }^{* * *} p<0.001$; medians are shown in graphs. $n=12$ experiments from 6 independent donors $(\mathbf{a}) ; n=7$ experiments from 7 independent donors (b); $n=7$ experiments from 4 independent donors (c); $n=8$ experiments from 5 independent donors (d); $n=$ 5 experiments from 4 independent donors (e). NHEK, normal human epidermal keratinocyte;ns, non-stimulated; MFI, mean fluorescence intensity; CTSL, cathepsin L; inh., inhibitor; tgt/ref, target/reference; C3a, active C3 fragment. 


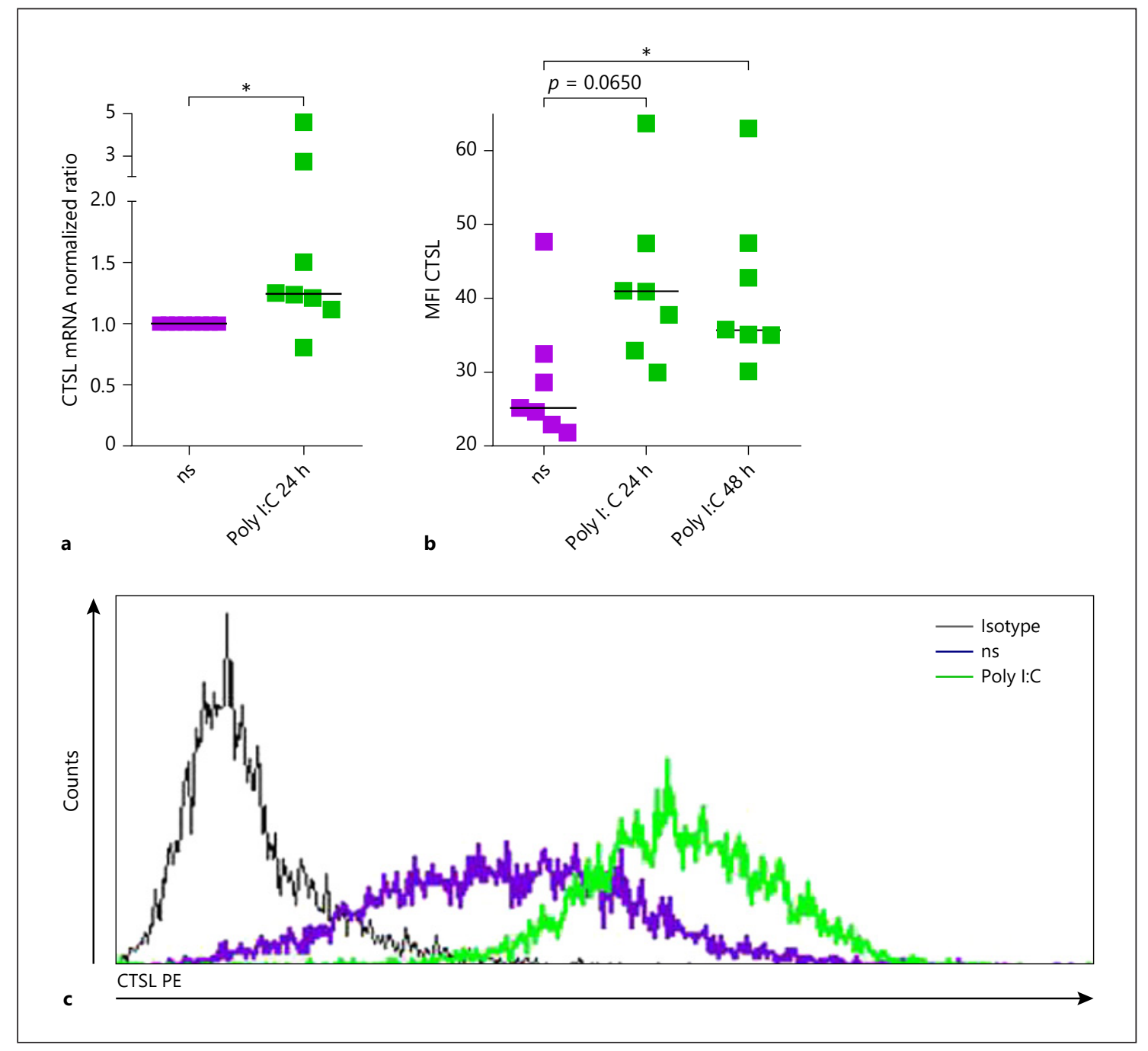

Fig. 4. TLR3 ligand Poly I:C up-regulates CTSL mRNA and protein expression in NHEKs. NHEKs were stimulated with Poly I:C (10 $\mu \mathrm{g} /$ $\mathrm{mL}$ ) for $24 \mathrm{~h}$ (for mRNA expression) and $24 \mathrm{~h}$ or $48 \mathrm{~h}$ (protein production) or left unstimulated. a CTSL mRNA expression was analysed by qPCR and calculated by the [delta] [delta] Ct method normalized to the ns samples. Phosphoglycerate kinase 1 was used as reference gene. $\mathbf{b}$ Intracellular expression of CTSL was analysed by flow cytometry, and MFIs were calculated. c One representative histogram of intracellular CTSL expression is shown. The dotted line represents the matched isotype control, the violet line represents the ns cells, and the green line represents the Poly I:C-stimulated cells. Significant differences, as determined by the Wilcoxon matchedpairs signed rank test (a) or by Friedman-Dunn's multiple comparison test selected pairs (b), are indicated as follows: ${ }^{*} p<0.05$; medians are shown in the graphs. $n=8$ experiments from 8 independent donors (a); $n=7$ experiments from 4 independent donors (b). NHEK, normal human epidermal keratinocyte; ns, non-stimulated; MFI, mean fluorescence intensity; CTSL, cathepsin L.
CTSL inhibitor. These experiments show that the CTSL inhibitor works selectively, has no toxic effects, and does not influence the regulation of C3 mRNA expression.

\section{Poly I:C Up-Regulates CTSL mRNA and Protein Expression in NHEKs}

To prove if CTSL is expressed and also regulated by Poly I:C in NHEKs, mRNA and protein expression of
CTSL in response to Poly I:C was investigated by PCR and flow cytometry. We detected a constitutive expression of CTSL at mRNA and protein levels in NHEKs. By stimulating TLR3 on keratinocytes with Poly I:C, the expression of CTSL mRNA $(24 \mathrm{~h})$ and protein $(24$ and $48 \mathrm{~h})$ was up-regulated (Fig. $4 \mathrm{a}-\mathrm{c}$ ). 


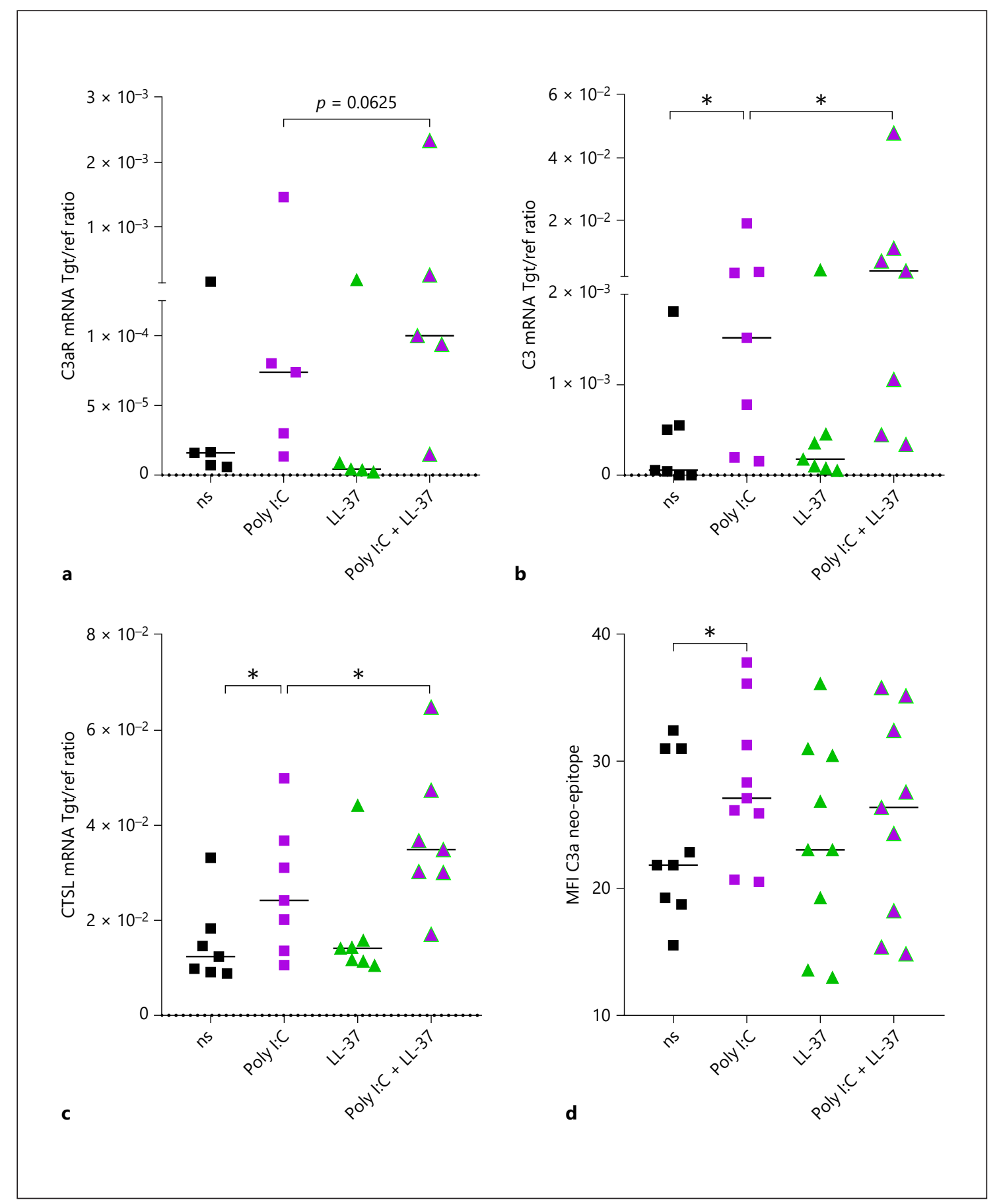

Fig. 5. Cathelicidin antimicrobial peptide LL-37 potentiates Poly I:C-induced up-regulation of C3aR, C3, and CTSL mRNA expression in NHEKs. NHEKs were stimulated with (i) Poly I:C $(10 \mu \mathrm{g} /$ $\mathrm{mL}$ ), (ii) LL-37 (1 $\mu \mathrm{M})$, (iii) Poly I:C $(10 \mu \mathrm{g} / \mathrm{mL})$ in combination with LL-37 $(1 \mu \mathrm{M})$ for $24 \mathrm{~h}$ or left unstimulated. C3aR mRNA expression (a), C3 mRNA expression (b), CTSL mRNA expression (c), C3a neo-epitope generation (d). mRNA expressions were analysed by qPCR and calculated by the [delta] Ct method. tgt/ref ratios are depicted. Phosphoglycerate kinase 1 was used as reference gene. The expression of C3a was analysed by flow cytometry, and MFIs were calculated. Significant differences, as determined by the Wilcoxon matched-pairs signed rank test are indicated as follows: ${ }^{*} p<0.05$; medians are shown in the graphs. $n=5$ experiments from 4 independent donors (a), $n=7$ experiments from 6 independent donors (b), $n=7$ experiments from 6 independent donors (c), $n=9$ experiments from 3 independent donors (d). NHEK, normal human epidermal keratinocyte; tgt/ref, target/reference ratio; ns, non-stimulated; MFI, mean fluorescence intensity; CTSL, cathepsin L; C3aR, anaphylatoxin C3a receptor; C3a, active C3 fragment. 
Cathelicidin Antimicrobial Peptide LL-37 Potentiates the Poly I:C-Induced Up-Regulation of C3aR, C3, and CTSL mRNA Expression in NHEKs

The antimicrobial peptide LL-37 is able to bind DNA, and this complex can trigger the endosomally expressed TLR9, enhancing the responsiveness of TLR9 in human keratinocytes [19]. LL-37 increases expression of INF- $\beta$ and thereby the antiviral activity against herpes simplex virus. LL-37, synergistically with Poly I:C, enhances INF- $\beta$ expression in NHEKs [8]. In addition, LL-37 can form pro-inflammatory nanocrystalline complexes with dsRNA that are recognized by TLR3, leading to increased cytokine production, in particular of IL-6 production [20].

According to these experiments, we investigated whether LL-37 also affects the C3a/C3aR axis in synergy with Poly I:C. We used for these experiments NHEKs which had stable effects but did not show substantial responses to Poly I:C stimulation. Based on more comparable and homogenous responses to Poly I:C in these donors, we hypothesized that the effect of LL-37 to enhance Poly I:C-induced signalling, as shown in previous studies, will be more easily detectable. These pre-selected NHEKs were stimulated with Poly I:C in combination with LL-37 for $24 \mathrm{~h}$, and C3aR, C3, CTSL mRNA expression and generation of C3a were measured. As depicted in Figure 5ac, the Poly I:C-induced up-regulation of C3aR, C3, and CTSL mRNA expression were further potentiated by LL37, whereas LL-37 had no effect on the amount of C3a generation by Poly I:C (Fig. 5d). Stimulation by LL-37 alone did not influence expression of these components.

$C 3 a R, C 3$, the Active Fragment of $C 3$, the C3/

C3a Neo-Epitope, and the Protease CTSL Are

Differentially Expressed in Normal Human Epidermis and in NHEKs Cultured in Low $\mathrm{Ca}^{2+}$ Concentrations Compared to NHEKs Cultured in High $\mathrm{Ca}^{2+}$

\section{Concentrations}

We investigated the expression of $\mathrm{C} 3 \mathrm{aR}, \mathrm{C} 3, \mathrm{C} 3 \mathrm{a}$, and CTSL by immunohistochemistry in normal human skin. We detected C3aR predominantly expressed in the basal layers, whereas $\mathrm{C} 3$ was predominantly expressed in the upper epidermal layers. The cleaving product of $\mathrm{C} 3$, the anaphylatoxin $\mathrm{C} 3 \mathrm{a}$, was also present in the basal layers but more pronounced in the supra-basal layers. CTSL expression was equally distributed in the different epidermal layers (Fig. 6a-d). Staining with the corresponding isotypes revealed no unspecific binding (Fig. 6m, n).

The differentiation of keratinocytes in cell culture and in vivo in different layers in the epidermis is mainly controlled by a gradient of extracellular $\mathrm{Ca}^{2+}$ ions with low levels in the basal layers, comprising immature proliferating cells, and with high levels of $\mathrm{Ca}^{2+}$ ions in the upper layers, which are formed by terminally differentiated cells [21]. Therefore, we investigated NHEKs in culture conditions mimicking the differentiation process of keratinocytes. To do this, we cultured NHEKs in chamber tek slides. NHEKs were left undifferentiated or were differentiated in the presence of high $\mathrm{Ca}^{2+}$ concentrations. After fixation of the cells, immunohistochemistry was performed, applying the C3aR-, C3-, C3a-, and CTSL-specific antibodies in the same concentrations as used in normal human skin. In accordance with the immunohistochemistry picture in the skin, we observed high C3aR expression in undifferentiated (Fig. 6i) and lower C3aR expression levels in NHEKs which were differentiated in high $\mathrm{Ca}^{2+}$ concentrations (Fig. 6e). Expression of $\mathrm{C} 3$ and C3a neo-epitope indicated a tendency to be highly expressed in NHEKs which were differentiated in high $\mathrm{Ca}^{2+}$ concentrations (Fig. 6f, g) when compared to undifferentiated cells (Fig. 6j, k). CTSL was noticed to be uniformly expressed in undifferentiated and in cells differentiated in high $\mathrm{Ca}^{2+}$ concentrations (Fig. 6h, 1). Staining with the corresponding isotypes revealed no unspecific binding (Fig. 6o, p).

$m R N A$ and Protein Expression of C3aR, C3/C3a Neo-Epitope, and Protease CTSL Are Differentially Regulated in NHEKs Cultured in Low $\mathrm{Ca}^{2+}$

Concentrations Compared to NHEKs Cultured in

High $\mathrm{Ca}^{2+}$ Concentrations

We differentiated NHEKs in the presence of low or high $\mathrm{Ca}^{2+}$ concentrations to investigate the expression levels of C3aR, C3/C3a neo-epitope, CTSL, and differentiation markers keratin 14 and filaggrin. As expected from the immunohistochemistry data showing high $\mathrm{C} 3 \mathrm{aR}$ expression in the proliferating basal layers of the epidermis or in NHEKs cultured in low $\mathrm{Ca}^{2+}$ concentrations on chamber tek slides, we observed also a higher expression of $\mathrm{C} 3 \mathrm{aR}$ mRNA levels in undifferentiated NHEKs cultured with low $\mathrm{Ca}^{2+}$ concentrations when compared to mRNA levels in terminally differentiated cells cultured with high $\mathrm{Ca}^{2+}$ concentrations (Fig. 7a). This result was confirmed at the protein level by flow cytometry where the intracellular staining of $\mathrm{C} 3 \mathrm{aR}$ showed high $\mathrm{C} 3 \mathrm{aR}$ expression in undifferentiated cells and reduced expression in the $\mathrm{Ca}^{2+}$ differentiated cells (Fig. 7d). Vice versa, C3 mRNA expression levels were higher in cells cultured in high $\mathrm{Ca}^{2+}$ concentrations when compared to C3 mRNA expression levels in cells cultured in low $\mathrm{Ca}^{2+}$ concentrations (Fig. $7 \mathrm{~b}$ ). This is in contrast to 


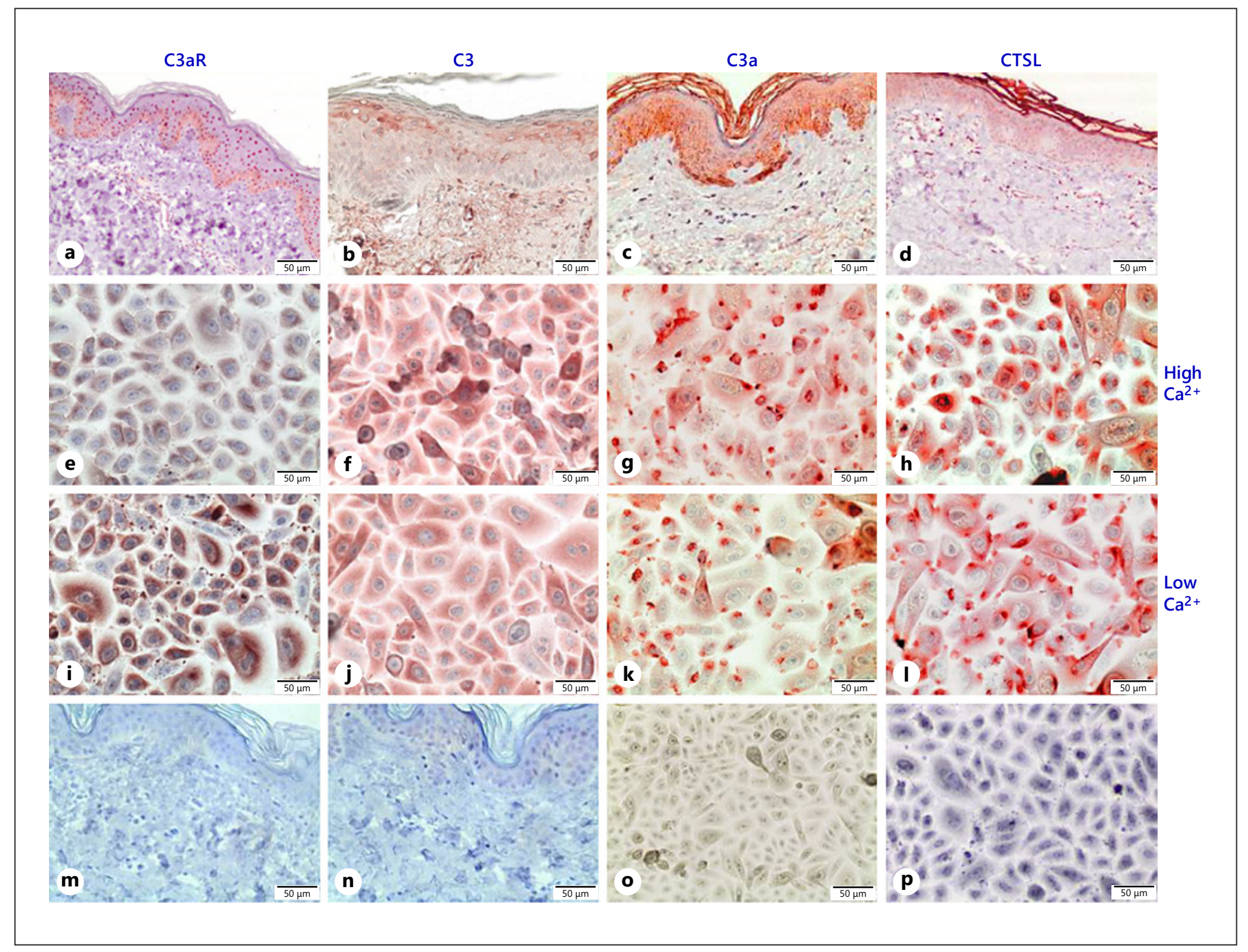

Fig. 6. $\mathrm{C} 3 \mathrm{aR}, \mathrm{C} 3$ the active fragment of $\mathrm{C} 3$, the anaphylatoxin $\mathrm{C} 3 \mathrm{a}$, and the protease CTSL are differentially expressed in normal human epidermis and in NHEKs cultured in low $\mathrm{Ca}^{2+}$ concentrations compared to NHEKs cultured in high $\mathrm{Ca}^{2+}$ concentrations. C3aR expression (rabbit polyclonal, Abcam, Cambridge, UK) (a), C3 expression (rabbit polyclonal, Abcam, Cambridge, UK) (b), C3a expression (monoclonal mouse IgG1, Hycult Biotech, Uden, The Netherlands) (c), and CTSL (monoclonal mouse IgG1, Abcam) (d) expression were detected in the epidermis in skin biopsies of normal human skin by immunohistochemistry. Staining with the corresponding isotypes showed no unspecific binding in the epidermis in skin biopsies of normal human skin by immunohistochemistry. $\mathbf{m}$ Mouse IgG1. $\mathbf{n}$ Rabbit polyclonal IgGs. One example for each target out of 4 different immunohistochemistry stainings of human skin is shown. NHEKs from different donors were cultured in chamber tek slides in medium containing $0.06 \mathrm{mM} \mathrm{CaCL}_{2}$ (low calcium conditions) and $1.36 \mathrm{mM} \mathrm{CaCL}_{2}$ (high calcium condi- tions) for 3 days and stained by immunohistochemistry. C3aR expression in high calcium conditions (e), C3aR expression in low calcium conditions (rabbit polyclonal, Abcam, Cambridge, UK) (i), C3 expression in high calcium conditions (f), C3 expression in low calcium conditions (rabbit polyclonal, Abcam, Cambridge, UK) (j), C3a expression in high calcium conditions (g), C3a expression in low calcium conditions (monoclonal mouse IgG1, Hycult Biotech, Uden, The Netherlands) (k), CTSL expression in high calcium conditions (h), CTSL expression in low calcium conditions (monoclonal mouse IgG1, Abcam) (I). Staining with the corresponding isotypes showed no unspecific binding by immunohistochemistry. o Mouse IgG1. p Rabbit polyclonal IgGs. One example for each target and condition out of 4 different immunohistochemistry stainings of NHEKs on chamber tek slides is shown. CTSL, cathepsin L; NHEK, normal human epidermal keratinocyte; $\mathrm{C} 3 \mathrm{aR}$, anaphylatoxin $\mathrm{C} 3 \mathrm{a}$ receptor; $\mathrm{C} 3 \mathrm{a}$, active $\mathrm{C} 3$ fragment. 


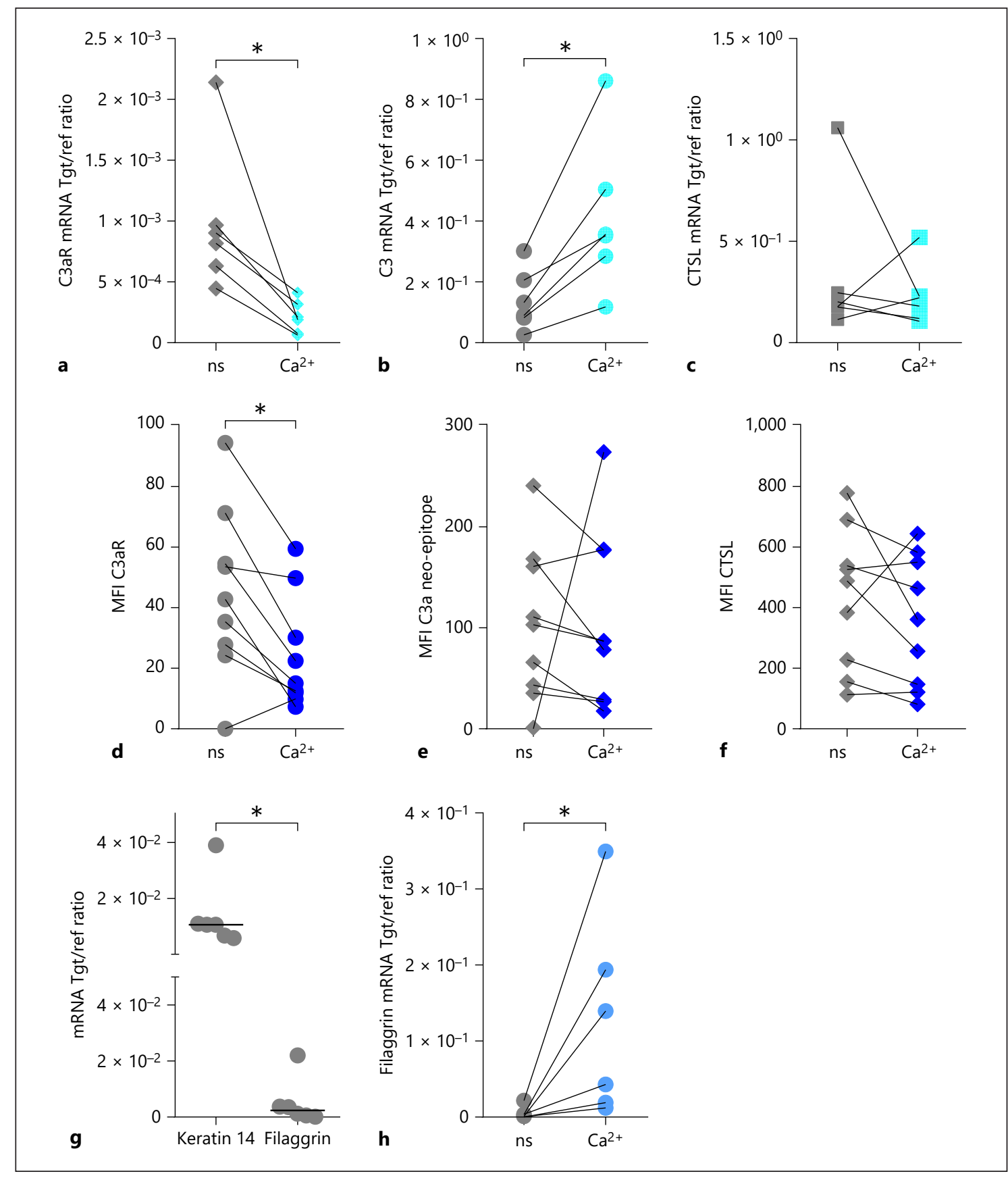

Fig. 7. $\mathrm{mRNA}$ and protein expression of $\mathrm{C} 3 \mathrm{aR}, \mathrm{C} 3 / \mathrm{C} 3 \mathrm{a}$ neo-epitope, and protease CTSL are differentially regulated in NHEKs cultured in low $\mathrm{Ca}^{2+}$ concentrations compared to NHEKs cultured in high $\mathrm{Ca}^{2+}$ concentrations. NHEKs from different donors were cultured in medium containing $0.06 \mathrm{mM} \mathrm{CaCL} 2$ (low calcium conditions) and $1.36 \mathrm{mM} \mathrm{CaCL}_{2}$ (high calcium conditions) $\left(\mathrm{Ca}^{2+}\right)$ for 3 days. a C3aR mRNA tgt/ref ratio was analysed. b C3 mRNA tgt/ref ratio was analysed. c CTSL mRNA tgt/ref ratio was analysed. C3aR expression (d), C3a neoepitope expression (e), and CTSL expression were measured intracellularly by flow cytometry (f). g Keratin 14 mRNA and filaggrin mRNA tgt/ref ratios were analysed. Keratin 14 is highly expressed in cells cultured in low calcium conditions when compared to filaggrin. $\mathbf{h}$ Filaggrin mRNA tgt/ref ratio was analysed. Filaggrin mRNA is moderately expressed in undifferentiated cells cultured in low $\mathrm{Ca}^{2+}$ concentrations and up-regulated in cells differentiated in the presence of high $\mathrm{Ca}^{2+}$ concentrations. Phosphoglycerate kinase 1 was used as reference gene. Significant differences, as determined by the Wilcoxon matched-pairs signed rank test, are indicated as follows: ${ }^{*} p<0.05 ; \mathbf{g}$ medians are shown in the graph. a-c, $\mathbf{g}, \mathbf{h} n=6$ experiments from 5 independent donors); (d-f, $n=$ 9 experiments from 9 independent donors). NHEK, normal human epidermal keratinocyte; ns, non-stimulated; MFI, mean fluorescence intensity; CTSL, cathepsin L; C3aR, anaphylatoxin C3a receptor; tgt/ref, target/reference; C3a, active C3 fragment. 
intracellular staining and flow cytometry analysis of the cleavage product of $\mathrm{C} 3$, the $\mathrm{C} 3 \mathrm{a}$ neo-epitope (Fig. 7e). The flow cytometry analysis revealed no difference in the expression levels of $\mathrm{C} 3 \mathrm{a}$ neo-epitope between the cells cultured in low or high $\mathrm{Ca}^{2+}$ concentrations. The mRNA and protein expression of CTSL was not influenced by different $\mathrm{Ca}^{2+}$ concentrations (Fig. 7c, f). The progression of keratinocyte maturation is characterized by expression of characteristic differentiation markers for early or late stages of differentiation. The type I keratin K14 is highly expressed in undifferentiated cells comprising the basal layers within the epidermis and represents an early-stage marker, whereas filaggrin is processed from stores of profilaggrin and densely packed in cornified cells and represents a marker of terminal differentiation of keratinocytes [22]. Correspondingly, we observed high mRNA expression levels of keratin 14 in undifferentiated cells cultured in low $\mathrm{Ca}^{2+}$ concentrations and high expression of filaggrin mRNA levels in matured cells cultured with high $\mathrm{Ca}^{2+}$ concentrations (Fig. 7g, h), confirming that a gradient of extracellular $\mathrm{Ca}^{2+}$ concentrations influences the differentiation of NHEKs also in our in vitro conditions.

\section{Discussion}

Complement activation not only occurs at extracellular sites via classical, lectin, or alternative pathways but also intracellularly in T lymphocytes upon the engagement of TCR on T cells. This leads to enhanced intracellular expression of C3aR and C3, followed by intracellular activation of $\mathrm{C} 3$ and generation of the active fragment C3a through the proteolytic capacity of CTSL (Liszewski et al. [16]). It was speculated that these mechanisms were also present and of physiological relevance in human keratinocytes. Here, we show for the first time high levels of intracellular protein expression of $\mathrm{C} 3 \mathrm{a}$ and intracellular $\mathrm{C} 3 \mathrm{aR}$ in human keratinocytes.

As innate danger systems, TLRs and complement components play key roles in host defence by mobilization of innate and adaptive immunity. During infection, complement components and TLRs are rapidly activated, showing broad, but distinct, specificities by controlling inflammation and invading pathogens. However, an appropriately coordinated immune response would be improved by a molecular crosstalk between pathways of the TLRs and complement system, leading to synergistic or antagonistic interactions. Complement and TLR crosstalk mechanisms have been described for the human and murine systems $[1,23]$.
We examined the regulation of the $\mathrm{C} 3 \mathrm{a} / \mathrm{C} 3 \mathrm{aR}$ axis in NHEKs by treatment with different TLR ligands. Keratinocytes respond to dsRNA from virus-infected or damaged cells after injury with enhanced secretion of inflammatory cytokines $[7,11]$. This is of special interest as in chronic inflammatory skin diseases, persistent inflammation or injury following scratching promotes skin damage and release of dsRNA. IFN- $\gamma$, which is present in skin of chronic atopic dermatitis and psoriasis, up-regulates TLR3 expression in human keratinocytes [24].

Our in vitro study detected an up-regulation of $\mathrm{C} 3 \mathrm{aR}$, C3, and CTSL expression and generation of C3a upon stimulation of TLR3 by Poly I:C, mimicking dsRNA on NHEKs. Remarkably, incubation of the cells with a CTSL inhibitor blocked the Poly I:C-induced generation of C3a, whereas the constitutive expression of intracellularly localized C3a was not influenced after treatment with the CTSL inhibitor.

These data support our hypothesis that the elevated expression levels of CTSL caused by Poly I:C stimulation may ultimately lead to the increased generation of C3a. In this regard, CTSL may also play a role in intracellular complement activation by cleaving C3 into its components C3a and C3b in NHEKs.

We observed a variability showing a moderate to high response to Poly I:C between the different donors. It has to be taken into account that in contrast to cell lines, human primary cells reflect more an individual phenotype related to demographic or anamnestic characteristics of the donor.

We hypothesized that the accumulation of C3aR expression by Poly I:C will show biological or pathophysiological meanings by strengthening the efficacy of the response to $\mathrm{C} 3 \mathrm{a}$ by triggering the expression of $\mathrm{C} 3 \mathrm{aR}$-induced genes. Therefore, we measured the induction of the chemokines CCL2, CXCL8, and CXCL10 and of the complement component $\mathrm{C} 3$ via $\mathrm{C} 3 \mathrm{a}$ in non-stimulated and Poly I:C-activated NHEKs.

Opposed to our previous observation of an induction of CCL2, CXCL8, CXCL10, and C3 upon C3a stimulation after up-regulation of C3aR by IFN- $\gamma$ and IFN- $\alpha$ [13], we did not observe an up-regulation of CCL2 and CXCL8 via C3a after up-regulation the C3aR by Poly I:C. However, regarding the expression of the complement component $\mathrm{C} 3$, we observed that the production of $\mathrm{C} 3$ was decreased by trend by stimulating these cells, with $\mathrm{C} 3 \mathrm{a}$ showing a functional effect of the C3aR induction in Poly I:C-stimulated cells. This is in contrast to data of the previous publication where induction of C3aR by IFN $-\gamma$ and IFN- $\alpha$ resulted in an up-regulation of $\mathrm{C} 3$ via $\mathrm{C} 3 \mathrm{a}$ [13]. We sup- 
pose a more immunoregulatory effect of Poly I:C in combination with $\mathrm{C} 3 \mathrm{aR}$ stimulation when compared to the autocrine amplification loop of IFN- $\gamma$ and IFN- $\alpha$ in combination with $\mathrm{C} 3 \mathrm{aR}$ stimulation, as shown in our previous publication [13].

In accordance with the previous publication [13], production of CXCL10 was induced by Poly I:C and potentiated by trend by stimulating the NHEKs with C3a. CXCL10 binds to CXCR3, mediating immune responses by activation and recruitment of immune cells such as $\mathrm{T}$ cells, eosinophils, monocytes, and NK cells. Therefore, CXCL10 contributes to the perpetuation of inflammation [25].

Our data show that Poly I:C is able to regulate different components of the complement system such as $\mathrm{C} 3$ and $\mathrm{C} 3 \mathrm{a}$ and expression of the C3aR in NHEKs. The up-regulation of $\mathrm{C} 3 \mathrm{aR}$ and $\mathrm{C} 3 \mathrm{a}$ via Poly $\mathrm{I}: \mathrm{C}$ showed functional capacity by influencing and regulating Poly I:C-induced genes, for example, C3 and CXCL10.

Enhanced expression of the complement components was accompanied by an increase in the protease CTSL at mRNA and protein levels via TLR3. These observations may provide novel insights for a role of TLR3 in skin inflammation. Since the anaphylatoxin C3a is known to exert multiple pro-inflammatory functions involving cytokine/chemokine release from immune cells or attracting cells into the epidermis [26], the enhanced production of C3a via TLR3 in keratinocytes may lead to worsening of chronic skin inflammation. In situations where damaged and necrotic cells are abundant in skin, it is likely that TLR3 as a sensor of dsRNA from injured cells will be activated in a positive feedback loop, which reinforces inflammation.

We have shown by immunohistochemistry that complement components are differentially expressed in epidermal layers. C3aR was preferentially expressed in basal layers and in NHEKs cultured in low $\mathrm{Ca}^{2+}$ concentrations, and by contrast, C3 and C3a showed a trend to be expressed in upper layers of the epidermis and in NHEKs cultured in chamber teks in high $\mathrm{Ca}^{2+}$ concentrations. CTSL, which is supposed to be necessary to generate C3a, was not regulated by $\mathrm{Ca}^{2+}$ at mRNA and protein levels, and in consequence, the protease activity remained unchanged in the different conditions.

Regulation of complement components during crosstalk of TLR3 may take place in different epidermal layers. High expression levels of $\mathrm{C} 3 / \mathrm{C} 3 \mathrm{a}$ in terminally differentiated keratinocytes into the outermost layers of the epidermis can be of potential importance for the direct antimicrobial function of $\mathrm{C} 3 \mathrm{a}$, which has been shown to be in part comparable to the antimicrobial activity of cathelicidin antimicrobial peptide LL-37 [27].

LL-37 enhances the uptake of Poly I:C and thereby potentiates the Poly I:C-induced IFN- $\beta$ expression in human keratinocytes [8]. Interestingly, in our study, LL-37, in combination with Poly I:C, was able to potentiate the up-regulation of C3aR, C3, and CTSL mRNA expression levels in NHEKs, confirming the general picture that immune signaling can be highly influenced by antimicrobial peptide interactions and TLR-specific ligands.

In conclusion, we detected that $\mathrm{C} 3 \mathrm{aR}$ is highly expressed intracellularly in unstimulated NHEKs. The expression of C3aR, C3 mRNA, and protein; intracellular expression of CTSL; and the generation of C3a were upregulated by TLR3 stimulation.

These data may extend the previous findings in T cells and myeloid cells of an intrinsic generation of $\mathrm{C} 3 \mathrm{a}$ from intracellular stores of C3 [16] also to human keratinocytes. Our data lead to the presumption that activation of keratinocytes by Poly I:C may drive these functions comparable, as described for TCR stimulation in T cells [16]. However, further investigation is warranted to exactly establish the mechanisms underlying the intracellularly processing of $\mathrm{C} 3 \mathrm{a}$ in normal human epidermal keratinocytes.

\section{Acknowledgements}

The authors would like to thank Brigitta Koether and Gabriele Begemann for excellent technical assistance.

\section{Statement of Ethics}

The use of normal human epidermal keratinocytes generated from human foreskin or outer root sheath keratinocytes in research studies investigating inflammatory skin diseases was approved by the local Ethics Committee of the Hannover Medical School (Vote 2603-2015) and was conducted according to the Declaration of Helsinki Principles.

All participants in the study gave their written informed consent. The informed consent for human participants younger than 18 years was obtained from a parent and/or legal guardian. The study was approved by the local Ethics Committee and was in accordance with the protocols of the Declaration of Helsinki.

\section{Conflict of Interest Statement}

The authors declare no conflict of interest.
C3a and Its Receptor C3aR Are

Functionally Expressed in NHEKs
J Innate Immun 2021;13:164-178

DOI: $10.1159 / 000512547$ 


\section{Author Contributions}

S.M. is the primary author and analysed the C3aR and C3a expression on human keratinocytes, conducted data collection, analysis, interpretated the data, and wrote the first draft of the manuscript. L.D. performed most of the experiments, culturing and stimulating the keratinocytes and performing qPCR and FACS analyses. P.S. and F.H.B. performed part of the experiments. C.Z. acquired human keratinocytes from healthy donors. T.W. made significant and substantial contributions to the conception, design, and interpretation of the data. All authors reviewed, revised, and approved the manuscript for publication.

\section{References}

1 Kemper C, Köhl J. Novel roles for complement receptors in $\mathrm{T}$ cell regulation and beyond. Mol Immunol. 2013;56(3):181-90.

2 Hajishengallis G, Lambris JD. More than complementing tolls: complement-toll-like receptor synergy and crosstalk in innate immunity and inflammation. Immunol Rev. 2016;274(1):233-44.

3 Ricklin D, Hajishengallis G, Yang K, Lambris JD. Complement: a key system for immune surveillance and homeostasis. Nat Immunol. 2010;11(9):785-97.

4 Hartmann K, Henz BM, Krüger-Krasagakes S, Köhl J, Burger R, Guhl S, et al. C3a and C5a stimulate chemotaxis of human mast cells. Blood. 1997;89(8):2863-70.

5 Markiewski MM, Lambris JD. The role of complement in inflammatory diseases from behind the scenes into the spotlight. Am J Pathol. 2007;171(3):715-27.

6 Nestle FO, Di Meglio P, Qin JZ, Nickoloff BJ. Skin immune sentinels in health and disease. Nat Rev Immunol. 2009;9(10):679-91.

7 Weber F, Wagner V, Rasmussen SB, Hartmann R, Paludan SR. Double-stranded RNA is produced by positive-strand RNA viruses and DNA viruses but not in detectable amounts by negative-strand RNA viruses. J Virol. 2006;80(10):5059-64.

8 Takiguchi T, Morizane S, Yamamoto T, Kajita A, Ikeda K, Iwatsuki K. Cathelicidin antimicrobial peptide LL-37 augments interferon- $\beta$ expression and antiviral activity induced by double-stranded RNA in keratinocytes. Br J Dermatol. 2014;171(3):492-8.

9 Borkowski AW, Park K, Uchida Y, Gallo RL. Activation of TLR3 in keratinocytes increases expression of genes involved in formation of the epidermis, lipid accumulation, and epidermal organelles. J Invest Dermatol. 2013; 133(8):2031-40.

10 Werfel T, Allam JP, Biedermann T, Eyerich K, Gilles S, Guttman-Yassky E, et al. Cellular and molecular immunologic mechanisms in patients with atopic dermatitis. J Allergy Clin Immunol. 2016;138(2):336-49.
11 Lai Y, Di Nardo A, Nakatsuji T, Leichtle A, Yang Y, Cogen AL, et al. Commensal bacteria regulate toll-like receptor 3-dependent inflammation after skin injury. Nat Med. 2009; 15(12):1377-82.

12 Asgari E, Le Friec G, Yamamoto H, Perucha E, Sacks SS, Köhl J, et al. C3a modulates IL- $1 \beta$ secretion in human monocytes by regulating ATP efflux and subsequent NLRP3 inflammasome activation. Blood. 2013;122(20): 3473-81.

13 Purwar R, Wittmann M, Zwirner J, Oppermann M, Kracht M, Dittrich-Breiholz O, et al. Induction of $\mathrm{C} 3$ and CCL2 by C3a in keratinocytes: a novel autocrine amplification loop of inflammatory skin reactions. J Immunol. 2006;177(7):4444-50.

14 Schonthaler HB, Guinea-Viniegra J, Wculek SK, Ruppen I, Ximénez-Embún P, Guío-Carrión A, et al. S100A8-S100A9 protein complex mediates psoriasis by regulating the expression of complement factor C3. Immunity. 2013;39(6):1171-81

15 Werfel T, Kirchhoff K, Wittmann M, Begemann G, Kapp A, Heidenreich F, et al. Activated human $\mathrm{T}$ lymphocytes express a functional C3a receptor. J Immunol. 2000;165(11): 6599-605.

16 Liszewski MK, Kolev M, Le Friec G, Leung M, Bertram PG, Fara AF, et al. Intracellular complement activation sustains $\mathrm{T}$ cell homeostasis and mediates effector differentiation. Immunity. 2013;39(6):1143-57.

17 Glatzer F, Gschwandtner M, Ehling S, Rossbach K, Janik K, Klos A, et al. Histamine induces proliferation in keratinocytes from patients with atopic dermatitis through the histamine 4 receptor. J Allergy Clin Immunol. 2013;132(6):1358-67.

18 Zeitvogel J, Dalpke A, Eiz-Vesper B, Kracht M, Dittrich-Breiholz O, Werfel T, et al. Human primary keratinocytes show restricted ability to up-regulate suppressor of cytokine signaling (SOCS) 3 protein compared with autologous macrophages. J Biol Chem. 2012; 287(13):9923-30.
19 Morizane S, Yamasaki K, Mühleisen B, Kotol PF, Murakami M, Aoyama Y, et al. Cathelicidin antimicrobial peptide LL-37 in psoriasis enables keratinocyte reactivity against TLR9 ligands. J Invest Dermatol. 2012;132(1):13543.

20 Lee EY, Takahashi T, Curk T, Dobnikar J, Gallo RL, Wong GCL. Crystallinity of doublestranded RNA-antimicrobial peptide complexes modulates toll-like receptor 3-mediated inflammation. ACS Nano. 2017;11:1214555.

21 Popp T, Steinritz D, Breit A, Deppe J, Egea V, Schmidt A, et al. Wnt $5 \mathrm{a} / \beta$-catenin signaling drives calcium-induced differentiation of human primary keratinocytes. J Invest Dermatol. 2014;134(8):2183-91.

22 Moll R, Divo M, Langbein L. The human keratins: biology and pathology. Histochem Cell Biol. 2008;129(6):705-33.

23 Hawlisch H, Köhl J. Complement and tolllike receptors: key regulators of adaptive immune responses. Mol Immunol. 2006;43(12):13-21.

24 Kajita A, Morizane S, Takiguchi T, Yamamoto T, Yamada M, Iwatsuki K. Interferon-gamma enhances TLR3 expression and anti-viral activity in keratinocytes. J Invest Dermatol. 2015;135(8):2005-11.

25 Kuo PT, Zeng Z, Salim N, Mattarollo S, Wells JW, Leggatt GR. The role of CXCR3 and its chemokine ligands in skin disease and cancer. Front Med. 2018;5:271.

26 Zhang X, Kimura Y, Fang C, Zhou L, Sfyroera G, Lambris JD, et al. Regulation of toll-like receptor-mediated inflammatory response by complement in vivo. Blood. 2007;110(1):22836.

27 Nordahl EA, Rydengård V, Nyberg P, Nitsche DP, Mörgelin M, Malmsten M, et al. Activation of the complement system generates antibacterial peptides. Proc Natl Acad Sci U S A. 2004;101(48):16879-84. 